\title{
The Stockholm Spinal Cord Injury Study: 2. Associations between clinical patient characteristics and post-acute medical problems
}

\author{
$\mathrm{R}_{\text {Levi }}{ }^{1,2}, \mathrm{C}$ Hultling $^{1}$ and $\AA$ Seiger ${ }^{1,2}$ \\ ${ }^{1}$ Solberga SCI Research Project, ${ }^{2}$ Department of Clinical Neuroscience and Family Medicine, Karolinska \\ Institute, Huddinge University Hospital, S-126 91 Stockholm, Sweden
}

The Stockholm Spinal Cord Injury Study (SSCIS) is an extensive evaluation of a sample of 353 subjects with traumatic SCI, constituting $93 \%$ of the known regional prevalence population with this diagnosis. In a previous analysis of this group, symptoms such as pain, incontinence, sexual dysfunction and neurological deterioration, as well as secondary complications such as decubitus ulcers, urinary tract infections, spinal deformity and fractures, were found to be common. In the present report, we investigate associations between a few commonly used patient characteristics, ie gender, age at injury, duration of injury and extent of neurological compromise, and the occurrence of such problems, to assess differences in vulnerability in SCI subgroups. Results generally indicate an increased vulnerability in subjects with extensive neurological deficits, as well as a cumulation of complications with the increasing duration of injury. However, some exceptions are found, possibly indicating differences in temporal patterns of the occurrence of various complications, as well as certain gender-, age-, and lesion-associated variations in vulnerability. Symptoms directly related to the spinal cord lesion, eg neurogenic pain and neurological deterioration, seem to present rather soon post-injury. Males are more prone to experience excessive spasticity and sexual problems. Females experience more fractures and spinal deformity. Younger age at injury is associated with more spinal deformity but less severe pain problems. Higher age at injury is not found to be associated with more medical problems, with the exception of neurogenic pain, among post-acute, post-discharge survivors. The latter finding does not, however, preclude more such problems in the acute stage, since the present study neither addresses the pre-discharge period, nor includes information about mortality. Finally, the ASIA/IMSOP Impairment Scale Grade E-rated subjects were found to report problems to an extent that underlines the restricted sensorimotor sense in which this rating reflects recovery.

Keywords: spinal cord injury; epidemiology; outcome; complications; neurological deterioration; Stockholm Spinal Cord Injury Study

\section{Introduction}

With the dramatically improved survival rates achieved in the post-World War II era, increasing emphasis has been put on issues relating to the long term management of traumatic spinal cord injuries (SCI). Structured, comprehensive follow-up programmes are now advocated by most, if not all, centres in this segment of medicine. The need for such services has been elucidated in numerous studies of chronic SCI populations. ${ }^{1-7}$ Although differing in approach and design, these studies, taken together, point to the multitude of medical, psychosocial and economic issues that need to be addressed when caring for spinal man. The Stockholm Spinal Cord Injury Study (SSCIS) springs from the recent establishment of a centralised, regional SCI outpatient service. By implementing the availability of multiple sources for subject identification, an almost complete population has been identified. The SSCIS attempts to describe the current status of this near-total post-acute, post-discharge SCI population. In a first report, the medical panorama for the group as a whole was depicted. ${ }^{8}$ In the present study, we analyse the population by basic patient characteristics, for identification of differences in vulnerability as regards ill health and occurrence of complications.

\section{Subjects and methods}

The study group comprised 353 subjects with SCI, living in the Greater Stockholm area and the island of Gotland. This constituted $93 \%$ of all SCI subjects in the area. Information was obtained by interview and physical examination, performed by physicians and staff specialised in SCI, according to semi-structured protocols in all instances, and by the additional source of previous medical records in $96 \%$ of the cases. A detailed description of the methods employed for subject identification and investigation has recently been published. ${ }^{8}$ 
For the purposes of the present study, the subjects were grouped as follows:

- males versus females;

- cervical complete, cervical incomplete, thoracic complete, thoracic incomplete, lumbosacral complete, lumbosacral incomplete, and no (ASIA/IMSOP Impairment Scale Grade E) $)^{9}$ neurological sensorimotor lesion;

- age at injury was trichotomised as lower (3-20 years), intermediate (21-40 years), and higher (41-77 years) for the bivariate analyses, and was used as a continuous variable in the multivariate analyses (see below);

- duration of injury was trichotomised as shorter (0-4 years), intermediate (5-17 years), and longer (18-44 years) for the bivariate analyses, and was used as a continuous variable in the multivariate analyses (see below)

All statistical analyses were performed on Macintosh computers using the Statistical Package for the Social Sciences (SPSS). ${ }^{10}$ Analysis of contingency tables was performed to ascertain significant associations between each medical problem and subject characteristic. The Pearson $\chi^{2}$ test was used to calculate the probability of a given independence model.

Multivariate logistic regression analyses ${ }^{11}$ were performed in those instances where two or more of the subject characteristics concurrently showed bivariate associations with a given medical problem, so as to evaluate whether/how each of these characteristics was uniquely associated with the problem. The four independent variables (ie age at injury, duration of injury, gender and neurological classification) were used concurrently to predict the occurrence of a given problem. As stated previously, the variables duration of injury (in years) and age at injury (in years) were both entered as continuous variables in the multivariate logistic regression analysis. To provide a useful interpretation for these two variables, the estimated odds ratio for an increase of 10 years was given. For the gender variable, female sex was coded as 0 , and male sex as 1 . The neurological classification variable was contrast coded, with the ASIA/IMSOP Impairment Grade E group constituting the reference category, and entered as a block. The computed coefficients indicate multiplicative odds, ie the factor by which the odds change when increasing the value by one unit (in the case of the time variables), or as compared to the alternative in a dichotomy (in the case of the gender variable), or compared to the reference category (in the case of the neurological variables), while statistically controlling for all other variables in the model.

The model $\left(\chi^{2}\right)$ was used to evaluate the overall fit of the model. This statistic tests the hypothesis that the coefficients for the independent variables in the model, except the constant, are equal to zero. In addition, the significance of each regression coefficient was computed. This significance test is obtained by comparing the estimated regression coefficient to an estimate of its standard error. Ratios of less than -2 or greater than 2, were considered to deviate significantly from zero.

\section{Definitions of terminology}

The terms used in this paper were defined as stated below. These definitions were given to staff and subjects, and used consistently during the survey.

Complications: medical conditions associated with the SCI, usually diagnosed by a physician; the subjects who had experienced a given complication at least once since discharge from initial hospitalisation.

Symptoms: self-reported dysfunction and/or discomfort. If not specified otherwise below, the symptoms were experienced by the subjects within the last week at the time of study. Some common symptoms were explicitly asked for. Additionally, an open-ended question was given, asking for any other symptom.

Problems: ill health and impairments, secondary to complications and/or symptoms, as defined above.

Deep vein thrombosis, pulmonary embolism, septicaemia, pneumonia, fracture: as diagnosed by a physician, and documented in previous medical records.

Decubitus ulcer: erosion of skin due to pressure, and requiring treatment (surgical or conservative).

Urinary tract infection: symptomatic infection, verified by culture, and treated with antibiotics.

Urolithiasis: calculi in all locations within the urinary tract, and documented in previous medical records. Not necessarily symptomatic or requiring treatment.

Renal functional impairment: as diagnosed by a physician, and documented in previous medical records. Not necessarily symptomatic or requiring treatment.

Spinal deformity: structural or functional deformity of the spine, experienced by the subject and/or diagnosed by a physician and documented in previous medical records.

Progressive and/or new neurological symptoms: worsening, or de novo occurrence, of one or more of the following symptoms: motor or sensory loss (at, above, or below the neurological level of lesion); pain (any type, severity and location); spasticity; autonomic dysreflexia (verified and/or typical symptoms); hyperhidrosis (any location).

Pain: pain of long-standing duration, having a continuous negative impact on the perceived quality of life.

Neurogenic pain: classified as such by the physician, after eliciting a detailed pain history. Typically pain of a 
burning, stabbing or sharp-shooting quality segmentally at, or diffusely below the neurological level of lesion.

Non-neurogenic pain: classified as such by the physician, after eliciting a detailed pain history. Typically a load- or position-related pain of a throbbing or aching quality above the neurological level of lesion.

Pain-primary problem: pain perceived as such by the subject, when asked to consider all consequences of the SCI.

Spasticity problem: spasticity verified at the clinical examination and reported by the subject to restrict activities of daily life and/or to cause pain.

Bladder, bowel, and sexual function problems: overall bladder, bowel, or sexual dysfunction, perceived by subject as a 'moderate/severe' rather than 'none/minor' problem.

General medical symptoms: includes one or more of body weight fluctuation, decreased appetite, fatigue, excessive sweating, fever and itching.

Eye symptoms: includes visual impairment and 'any other eye symptom'.

Ear, nose and throat (ENT) symptoms: includes hearing impairment, frequent nosebleeds, tinnitus, hoarseness, and 'any other ENT symptom'.

Gastrointestinal symptoms: includes nausea/vomiting, abdominal pain, diarrhoea, rectal bleeding, heartburn, constipation, bloody vomiting.

Urogenital (UG) symptoms: includes discharge, haematuria, and 'any other UG symptom' not covered by the specific UG section above.

Respiratory symptoms: includes dyspnoea, cough, and 'any other respiratory symptom'.

Cardiovascular symptoms: includes ankle/leg oedema, chest pain, and palpitations.

Joint/muscular symptoms: includes joint pain, joint stiffness/contracture, soft tissue pain, soft tissue swelling.

Non-SCI-related neurological symptoms: includes syncope, headache, disturbed taste, disturbed olfaction, and seizures.

Mental symptoms: includes anxiety, depression, and sleep disturbance.

\section{Results}

\section{Bivariate analyses}

Tables 1-4 show the basic, bivariate, analyses of the patient gender, age at injury, duration of injury and neurological status, respectively, and their associations with medical complications and symptoms in the study group. Among the associations found in these tables, the following relationships between one single characteristic and a certain medical problem are particularly noteworthy:

- higher age at injury and neurogenic pain

- longer duration of injury and deep vein thrombosis

- longer duration of injury and gastrointestinal symptoms

- complete cervical injuries and renal function impairment

- complete cervical injuries and progressing/new spasticity

- complete cervical injuries and progressing/new hyperhidrosis

\section{Multivariate analyses}

As mentioned above, in the instances where two or more of the subject characteristics concurrently showed associations with a given medical problem in the bivariate analyses, multivariate logistic regression analyses were then performed so as to evaluate whether/ how each of these subject characteristics was uniquely associated with that particular medical problem.

Table 5 shows the results of these analyses. As is seen in this table, some of the associations between more than one patient characteristic and a certain medical problem were not confirmed in the multivariate analyses. In these instances, the bivariate associations were presumably due to confounding circumstances. In other instances, the association and its strength could be confirmed, as for:

- longer duration of injury and several medical complications

- lower age at injury and spinal deformity

- male sex and subjective sexual problems

- female sex and fractures and spinal deformity

- complete injuries and urinary tract infections and decubitus ulcers

- cervical injuries and spasticity problems

\section{Discussion}

For comments regarding accuracy of subject identification, accuracy of collected data and interpretation of demographics, see our previous article. ${ }^{8}$

\section{Data analysis}

The rarity of some medical problems may contribute to small expected frequencies, when analysing the contingency tables. Therefore, interpretation in these particular instances should be made with caution. 
Table 1 Associations between gender and medical problems

\begin{tabular}{|c|c|c|c|c|}
\hline & $\begin{array}{c}\text { Total } \\
n=353 \\
\%\end{array}$ & $\begin{array}{c}\text { Males } \\
n=286 \\
\%\end{array}$ & $\begin{array}{c}\text { Females } \\
n=67 \\
\%\end{array}$ & $\begin{array}{c}\chi^{2} \text {-test } \\
P\end{array}$ \\
\hline \multicolumn{5}{|l|}{ Complications } \\
\hline Deep vein thrombosis & 5 & 5 & 6 & 0.7188 \\
\hline Pulmonary embolism & 1 & 3 & 0 & 0.3303 \\
\hline Septicaemia & 7 & 8 & 5 & 0.3147 \\
\hline Pneumonia & 9 & 9 & 8 & 0.6717 \\
\hline Decubitus ulcer & 39 & 40 & 36 & 0.5770 \\
\hline Urinary tract infection & 67 & 67 & 69 & 0.8167 \\
\hline Urolithiasis & 21 & 23 & 12 & 0.0498 \\
\hline Renal functional impairment & 6 & 7 & 3 & 0.2219 \\
\hline Fracture & 20 & 18 & 30 & 0.0272 \\
\hline Spinal deformity & 23 & 21 & 31 & 0.0694 \\
\hline Other complication & 29 & 28 & 30 & 0.8032 \\
\hline No complication & 12 & 12 & 13 & 0.7279 \\
\hline \multicolumn{5}{|l|}{ Symptoms } \\
\hline General medical & 65 & 64 & 72 & 0.2356 \\
\hline One or more symptoms & 94 & 93 & 97 & 0.2545 \\
\hline Eye & 12 & 11 & 16 & 0.2389 \\
\hline Ear, nose and throat & 24 & 23 & 27 & 0.4722 \\
\hline Gastrointestinal & 49 & 51 & 40 & 0.1131 \\
\hline Urogenital & 12 & 11 & 15 & 0.3952 \\
\hline Respiratory & 18 & 16 & 30 & 0.0073 \\
\hline Cardiovascular & 58 & 55 & 69 & 0.0455 \\
\hline Joint/muscular & 53 & 51 & 60 & 0.2204 \\
\hline Non-SCI neurological & 28 & 27 & 30 & 0.6290 \\
\hline Mental & 48 & 49 & 42 & 0.2908 \\
\hline All-cause pain & 64 & 63 & 70 & 0.2674 \\
\hline Neurogenic pain & 47 & 47 & 49 & 0.7232 \\
\hline Non-neurogenic pain only & 17 & 16 & 21 & 0.3453 \\
\hline Spasticity & 68 & 72 & 54 & 0.0045 \\
\hline \multicolumn{5}{|c|}{ Progression of and/or new neurological symptoms } \\
\hline One or more symptoms & 33 & 33 & 30 & 0.5967 \\
\hline Decreased muscle power & 6 & 6 & 5 & 0.5717 \\
\hline Decreased sensation & 8 & 8 & 8 & 0.8746 \\
\hline Pain & 16 & 16 & 13 & 0.5902 \\
\hline Spasticity & 16 & 17 & 15 & 0.7119 \\
\hline Dysreflexia & 1 & 1 & 0 & 0.3999 \\
\hline Hyperhidrosis & 6 & 7 & 6 & 0.8408 \\
\hline \multicolumn{5}{|l|}{ Subjective functional problems } \\
\hline Pain primary problem & 29 & 29 & 27 & 0.6839 \\
\hline Spasticity problem & 28 & 29 & 25 & 0.5886 \\
\hline Bladder function problem & 40 & 37 & 49 & 0.0746 \\
\hline Bowel function problem & 38 & 38 & 40 & 0.7006 \\
\hline Sexual problem & 45 & 50 & 25 & 0.0004 \\
\hline
\end{tabular}

Nevertheless, such tables have generally been shown to be testable by the $\chi^{2}$ method. ${ }^{12}$ Since this study is mainly descriptive in character, no corrections for multiple tests have been done. The exact $P$ value has been given in order to allow judgement in terms of type I errors.

Temporal patterns of occurrence of medical problems With increasing duration of injury, the cumulated percentage of most complications show a successive increase. This reflects the fact that many complications can occur for the first time also many years post-injury.
However, whether the absolute risk for these complications is constant, increasing or decreasing with increasing duration of injury cannot be assessed in this study. Neither can the number of times (more than once) a complication occurs be elucidated, since the collected data only reflect whether or not the subject has experienced the complication.

In contrast, the prevalence of most symptoms does not seem to increase with increasing duration of injury. This is especially noteworthy as regards severe pain and neurological deterioration. It seems to be that such symptoms, if they are going to occur will do so rather soon after injury. Only cardiovascular symptoms show 
Table 2 Associations between age at injury and medical problems

\begin{tabular}{|c|c|c|c|c|c|}
\hline & \multirow{2}{*}{$\begin{array}{c}\text { Total } \\
n=353 \\
\%\end{array}$} & \multicolumn{3}{|c|}{ Age at injury (yrs) } & \multirow{2}{*}{$\begin{array}{c}\chi^{2} \text {-test } \\
P\end{array}$} \\
\hline & & $\begin{array}{c}3-20 \\
n=102 \\
\%\end{array}$ & $\begin{array}{c}21-40 \\
n=162 \\
\%\end{array}$ & $\begin{array}{c}41-77 \\
n=89 \\
\%\end{array}$ & \\
\hline \multicolumn{6}{|l|}{ Complications } \\
\hline Deep vein thrombosis & 5 & 7 & 6 & 2 & 0.3300 \\
\hline Pulmonary embolism & 1 & 2 & 1 & 0 & 0.4364 \\
\hline Septicaemia & 7 & 12 & 6 & 4 & 0.1162 \\
\hline Pneumonia & 9 & 16 & 6 & 7 & 0.0134 \\
\hline Decubitus ulcer & 39 & 54 & 36 & 25 & 0.0003 \\
\hline Urinary tract infection & 67 & 80 & 64 & 58 & 0.0027 \\
\hline Urolithiasis & 21 & 26 & 22 & 12 & 0.0517 \\
\hline Renal functional impairment & 6 & 8 & 7 & 2 & 0.1965 \\
\hline Fracture & 20 & 22 & 22 & 15 & 0.3227 \\
\hline Spinal deformity & 23 & 34 & 22 & 12 & 0.0013 \\
\hline Other complication & 29 & 28 & 30 & 26 & 0.7605 \\
\hline No complication & 12 & 8 & 14 & 15 & 0.2753 \\
\hline \multicolumn{6}{|l|}{ Symptoms } \\
\hline General medical & 65 & 68 & 67 & 61 & 0.5430 \\
\hline One or more symptoms & 94 & 93 & 93 & 98 & 0.2291 \\
\hline Eye & 12 & 8 & 11 & 19 & 0.0510 \\
\hline Ear, nose and throat & 24 & 14 & 20 & 40 & 0.0001 \\
\hline Gastrointestinal & 49 & 51 & 52 & 42 & 0.2657 \\
\hline Urogenital & 12 & 8 & 14 & 12 & 0.2960 \\
\hline Respiratory & 18 & 18 & 14 & 27 & 0.0431 \\
\hline Cardiovascular & 58 & 57 & 57 & 61 & 0.8164 \\
\hline Joint/muscular & 53 & 62 & 48 & 53 & 0.0784 \\
\hline Non-SCI neurological & 28 & 24 & 32 & 24 & 0.2972 \\
\hline Mental & 48 & 45 & 51 & 44 & 0.4441 \\
\hline All-cause pain & 64 & 54 & 67 & 71 & 0.0296 \\
\hline Neurogenic pain & 47 & 32 & 49 & 61 & 0.0004 \\
\hline Non-neurogenic pain only & 17 & 22 & 18 & 10 & 0.1006 \\
\hline Spasticity & 68 & 75 & 66 & 65 & 0.2729 \\
\hline \multicolumn{6}{|c|}{ Progression of and/or new neurological symptoms } \\
\hline One or more symptoms & 33 & 41 & 30 & 27 & 0.0777 \\
\hline Decreased muscle power & 6 & 3 & 7 & 7 & 0.3065 \\
\hline Decreased sensation & 8 & 5 & 9 & 10 & 0.3728 \\
\hline Pain & 16 & 21 & 12 & 17 & 0.1436 \\
\hline Spasticity & 16 & 21 & 16 & 12 & 0.3050 \\
\hline Dysreflexia & 1 & 0 & 1 & 1 & 0.5385 \\
\hline Hyperhidrosis & 6 & 11 & 4 & 6 & 0.1081 \\
\hline \multicolumn{6}{|l|}{ Subjective functional problems } \\
\hline Pain primary problem & 29 & 16 & 36 & 30 & 0.0014 \\
\hline Spasticity problem & 28 & 28 & 28 & 27 & 0.9663 \\
\hline Bladder function problem & 40 & 42 & 38 & 39 & 0.8186 \\
\hline Bowel function problem & 38 & 39 & 40 & 34 & 0.5891 \\
\hline Sexual problem & 45 & 45 & 52 & 32 & 0.0060 \\
\hline
\end{tabular}

a clear-cut increase in prevalence with a longer duration of injury. As was reported previously, ${ }^{8}$ ankle/leg oedema mainly accounts for this symptom group. Oedema may be secondary to lower-leg dependency, as well as from several disease processes, eg venous insufficiency, post-thrombotic syndrome, cardiac and renal disease, all of which are expected to become more prevalent with time.

Our study design does not allow for assessment of patterns of mortality in SCI subjects. In a recently published survey of deaths during the first 12 years after SCI by de Vivo et al, ${ }^{13}$ the leading causes were shown to be pneumonia, non-ischaemic heart disease, septicaemia and pulmonary emboli, all of which were significantly more prevalent in the SCI group as compared to the general population. These conditions appeared to have the greatest impact on the reduction of life expectancy and were found to occur early after SCI. In contrast, mortality patterns in subjects with a longer duration of SCI, such as our study group, were 
Table 3 Associations between duration of injury and medical problems

\begin{tabular}{|c|c|c|c|c|c|}
\hline & \multirow{2}{*}{$\begin{array}{c}\text { Total } \\
n=363 \\
\%\end{array}$} & \multicolumn{3}{|c|}{ Duration of injury (yrs) } & \multirow{2}{*}{$\begin{array}{c}\chi^{2}-\text { test } \\
P\end{array}$} \\
\hline & & $\begin{array}{c}0-4 \\
n=87 \\
\%\end{array}$ & $\begin{array}{c}5-17 \\
n=177 \\
\%\end{array}$ & $\begin{array}{c}18-44 \\
n=89 \\
\%\end{array}$ & \\
\hline \multicolumn{6}{|l|}{ Complications } \\
\hline Deep vein thrombosis & 5 & 0 & 5 & 10 & 0.0096 \\
\hline Pulmonary embolism & 1 & 0 & 2 & 0 & 0.1338 \\
\hline Septicaemia & 7 & 0 & 10 & 10 & 0.0101 \\
\hline Pneumonia & 9 & 2 & 9 & 15 & 0.0154 \\
\hline Decubitus ulcer & 39 & 22 & 38 & 56 & 0.0001 \\
\hline Urinary tract infection & 67 & 55 & 67 & 81 & 0.0013 \\
\hline Urolithiasis & 21 & 15 & 19 & 30 & 0.0267 \\
\hline Renal functional impairment & 6 & 2 & 6 & 10 & 0.1005 \\
\hline Fracture & 20 & 5 & 21 & 34 & 0.0001 \\
\hline Spinal deformity & 23 & 13 & 20 & 39 & 0.0001 \\
\hline Other complication & 29 & 14 & 28 & 45 & 0.0001 \\
\hline No complication & 12 & 18 & 14 & 3 & 0.0071 \\
\hline \multicolumn{6}{|l|}{ Symptoms } \\
\hline General medical & 65 & 69 & 63 & 67 & 0.5450 \\
\hline One or more symptoms & 94 & 95 & 94 & 92 & 0.6388 \\
\hline Eye & 12 & 9 & 13 & 14 & 0.6141 \\
\hline Ear, nose and throat & 24 & 15 & 25 & 29 & 0.0693 \\
\hline Gastrointestinal & 49 & 34 & 54 & 53 & 0.0075 \\
\hline Urogenital & 12 & 12 & 12 & 12 & 0.9843 \\
\hline Respiratory & 18 & 18 & 20 & 16 & 0.7245 \\
\hline Cardiovascular & 58 & 48 & 55 & 72 & 0.0043 \\
\hline Joint/muscular & 53 & 54 & 48 & 62 & 0.1022 \\
\hline Non-SCI Neurological & 28 & 23 & 32 & 24 & 0.2133 \\
\hline Mental & 48 & 49 & 51 & 39 & 0.1914 \\
\hline All-cause pain & 64 & 64 & 66 & 61 & 0.6838 \\
\hline Neurogenic pain & 47 & 41 & 49 & 49 & 0.4426 \\
\hline Non-neurogenic pain only & 17 & 23 & 17 & 11 & 0.1161 \\
\hline Spasticity & 68 & 71 & 70 & 63 & 0.4366 \\
\hline \multicolumn{6}{|c|}{ Progression or and/or new neurological symptoms } \\
\hline One or more symptoms & 33 & 33 & 32 & 33 & 0.9832 \\
\hline Decreased muscle power & 6 & 2 & 7 & 7 & 0.2481 \\
\hline Decreased sensation & 8 & 10 & 7 & 7 & 0.6220 \\
\hline Pain & 16 & 12 & 16 & 18 & 0.4539 \\
\hline Spasticity & 16 & 17 & 16 & 17 & 0.9506 \\
\hline Dysreflexia & 1 & 0 & 1 & 2 & 0.2256 \\
\hline Hyperhidrosis & 6 & 7 & 6 & 7 & 0.9732 \\
\hline \multicolumn{6}{|l|}{ Subjective functional problems } \\
\hline Pain primary problem & 29 & 29 & 28 & 30 & 0.9384 \\
\hline Spasticity problem & 28 & 31 & 28 & 26 & 0.7369 \\
\hline Bladder function problem & 40 & 36 & 40 & 43 & 0.6226 \\
\hline Bowel function problem & 38 & 32 & 41 & 38 & 0.3630 \\
\hline Sexual problem & 45 & 47 & 46 & 42 & 0.7326 \\
\hline
\end{tabular}

found to be more in accordance with that of the general population. This is also corroborated by a study by Whiteneck et al. ${ }^{5}$

General comments about indicators of vulnerability The present study focuses on a few commonly used patient characteristics, and their association with some medical problems commonly encountered after SCI. Some general comments regarding the limitations of categorisation by these characteristics may be made. Although SCI represents a fairly homogeneous group in comparison with, for instance, traumatic brain injury, and therefore more easily lends itself to a standardised classification, many differences of possible relevance for outcome do exist. The neurological lesion per se shows great variation both in craniocaudal localisation and segmental extension. The common classification in paraplegic and in tetraplegic individuals is of obvious relevance, eg in terms of the prediction of outcome as regards functional independence; but several other classifications could be as relevant, depending on the purpose. For instance, the division into those with a neural lesion above or below the mid-thoracic 
Table 4 Associations between neurological status and medical problems

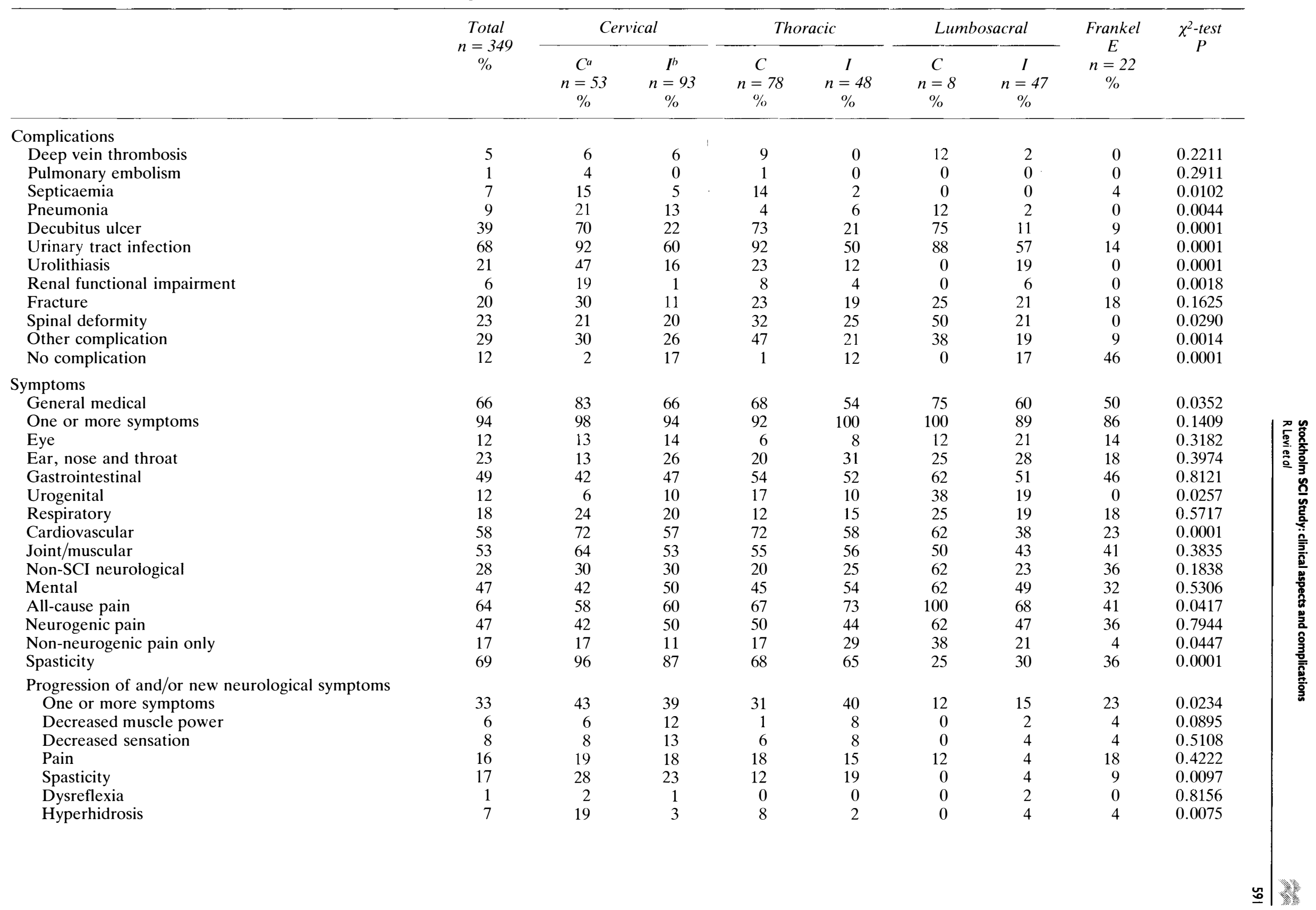


Table 4 (Cont)

\begin{tabular}{|c|c|c|c|c|c|c|c|c|}
\hline \multirow{2}{*}{$\begin{array}{c}\text { Total } \\
n=349 \\
\%\end{array}$} & \multicolumn{2}{|c|}{ Cervical } & \multicolumn{2}{|c|}{ Thoracic } & \multicolumn{2}{|c|}{ Lumbosacral } & \multirow{2}{*}{$\begin{array}{c}\text { Frankel } \\
E \\
n=22 \\
\%\end{array}$} & \multirow{2}{*}{$\begin{array}{c}\chi^{2}-t e s t \\
P\end{array}$} \\
\hline & $\begin{array}{c}C^{a} \\
n=53 \\
\%\end{array}$ & $\begin{array}{c}I^{b} \\
n=93 \\
\%\end{array}$ & $\begin{array}{c}C \\
n=78 \\
\%\end{array}$ & $\begin{array}{c}I \\
\substack{=\\
\%}\end{array}$ & 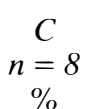 & $\begin{array}{c}I \\
n=47 \\
\%\end{array}$ & & \\
\hline
\end{tabular}

Table 5 Multivariate logistic regression models for the relationship between duration of injury, age at injury, sex, neurological status, and medical problems Non-significant regression coefficients (coefficients not significantly deviating from 1) are omitted. See text (in method section and in the results) for further explanation

\begin{tabular}{|c|c|c|c|c|c|c|c|c|c|c|c|}
\hline & \multicolumn{3}{|c|}{ Independent variables ${ }^{a}$} & \multicolumn{6}{|c|}{ Neurological classification } & \multicolumn{2}{|c|}{ Model $\chi^{2} d f=9$} \\
\hline & $\begin{array}{l}\text { Dur } \\
\text { SCI }\end{array}$ & $\begin{array}{l}\text { Age } \\
\text { SCI }\end{array}$ & $\begin{array}{c}\text { Male } \\
\text { sex }\end{array}$ & $\begin{array}{c}\text { Cerv } \\
\text { comp }\end{array}$ & $\begin{array}{l}\text { Cerv } \\
\text { incpl }\end{array}$ & $\begin{array}{l}\text { Thor } \\
\text { comp }\end{array}$ & $\begin{array}{l}\text { Thor } \\
\text { incpl }\end{array}$ & $\begin{array}{c}L S \\
\text { comp }\end{array}$ & $\begin{array}{c}L S \\
\text { incpl }\end{array}$ & $\chi^{2}$ & $P$ \\
\hline \multicolumn{12}{|l|}{ Complications } \\
\hline Septicaemia & & & & & & & & & & 25.3 & 0.0027 \\
\hline Pneumonia & 1.7 & & & & & & & & & 27.5 & 0.0012 \\
\hline Decubitus ulcer & 1.8 & & & 21.1 & & 21.4 & & 24.7 & & 129.8 & 0.0001 \\
\hline Urinary tract infection & 1.7 & & & 74.2 & 9.1 & 64.7 & 5.4 & 36.9 & 7.9 & 99.6 & 0.0001 \\
\hline Urolithiasis & 1.5 & & & & & & & & & 46.8 & 0.0001 \\
\hline Fracture & 2.4 & & 0.5 & & & & & & & 44.0 & 0.0001 \\
\hline Spinal deformity & 1.9 & 0.7 & 0.5 & & & & & & & 53.1 & 0.0001 \\
\hline Other complication & 1.8 & & & & & 6.9 & & & & 41.3 & 0.0001 \\
\hline No complication & 0.4 & & & 0.1 & 0.3 & 0.1 & 0.2 & & 0.3 & 52.6 & 0.0001 \\
\hline \multicolumn{12}{|l|}{ Symptoms } \\
\hline Respiratory symptoms & & & 0.5 & & & & & & & 14.1 & 0.1177 \\
\hline Cardiovascular symptoms & 1.7 & & 0.5 & 9.4 & 4.1 & 8.0 & 4.4 & & & 48.8 & 0.0001 \\
\hline All-cause pain & & & & & & 3.2 & 4.1 & & 3.0 & 19.3 & 0.0228 \\
\hline Spasticity & & & 2.6 & 48.9 & 15.4 & 4.1 & 3.6 & & & 102.7 & 0.0001 \\
\hline \multicolumn{12}{|l|}{ Subjective functional problems } \\
\hline Sexual problem & 0.7 & & 3.0 & & & 3.6 & & 8.1 & & 41.9 & 0.0001 \\
\hline
\end{tabular}

aThe independent variables were coded as follows: both Duration of SCI and Age at SCI were measured in years, and defined as continuous variables. The multiplicative odds for these variables have been transformed to offer an interpretation based on a 10 year increase. For the gender variable, female sex was coded as 0 , and male sex as 1 . The neurological classification variable was contrast coded with the Frankel E group constituting the reference category 
level, when assessing the risk for autonomic dysreflexia, or division into those with an upper versus those with a lower motor neuron lesion when considering spasticity, bowel, bladder, and sexual function are examples of such relevant alternative classifications. Furthermore, the variability as regards incompleteness of the lesion goes far beyond the commonly used neuroanatomical syndromes. For instance, even lesions classified as complete, may in fact be further subdivided into true 'complete', as opposed to 'discomplete', lesions. ${ }^{14}$ The neurological classification used in this study, although more detailed than for example, the not seldom used 'para/tetra, complete/incomplete' scheme, is still crude in a neurobiological context.

Additionally, SCI is often accompanied by injuries to extraspinal organ systems. Substantial musculoskeletal, brain, lung, and intra-abdominal injuries are not uncommon. All these and other variables, individually and in combinations, are likely to affect the long term outcome. This adds to the justified caution by which conclusions about causality should be drawn from simplified models for the investigation of associations. Nevertheless, such associations may be clinically useful as indicators of increased vulnerability in certain subgroups for certain problems.

\section{Gender as a vulnerability indicator}

The finding of an association between male sex and more subjective sexual problems is expected from the differences in physiology, and the impact of erectile and procreational dysfunction on male sexuality. In contrast, the stronger association with spasticity problems in the male is less obvious. The finding of more fractures and spinal deformity in females is noteworthy. The reason for this is unknown, but may be related to the more delicate structure of the female skeleton, and/or the accelerated rate of skeletal demineralisation known to occur in females at the menopause.

\section{Age at injury as a vulnerability indicator}

The only statistically significant associations found in this study between the age at injury and medical problems was between a higher age at injury and neurogenic pain, and between a younger age at injury and spinal deformity. While the latter finding in itself is not surprising, because of the impact of SCI on the growing spine as regards the development of scoliosis, one might have expected more massive indications of risk as regards a higher age at injury. However, this cannot be taken as an indication that overall morbidity and mortality is uninfluenced by the age at injury, since this study does not address medical problems in the acute stage, nor does its design make possible any evaluation of mortality. In fact, several earlier studies have shown mortality, particularly in the early stage, to be strongly associated with a higher age at injury. $5,15,16$ Our results indicate the morbidity among survivors in the post-acute, post-discharge stage.
Neurological vulnerability indicators

Not surprisingly, those with a complete cervical injury show strong associations with many of the medical problems encountered after SCI. A high degree of vulnerability can also be seen for those with a complete injury, regardless of the neurological level, as regards several important conditions. Again, when interpreting our data, it is important to remember that the present study does not address mortality. For instance, although our findings do not reveal any association between cervical injuries and pneumonia, which in fact has been shown to be a major cause of death among tetraplegics, ${ }^{13,17}$ this certainly does not preclude such an association. It merely suggests that this complication is not overrepresented among tetraplegic patient survivors.

Samsa et $a l^{15}$ conclude that the relationship between the level of injury and mortality, although very strong in the short term, is at most moderately strong in the medium to long term.

It is interesting to note the comparatively small difference in reported problems between the ASIA/ IMSOP Impairment Grade E subjects and their more severely neurologically injured counterparts. Although the small numbers available in this study, as well as lack of normative population data, precludes much more than speculation at this stage, some of the commonly reported problems in this group (eg neurogenic pain and spasticity) are rare in the normal population, and highly probable to be sequelae of a SCI. Our findings may serve as an indication that this group, although recovered in the restricted sensorimotor sense, may still have substantial impairments due to injuries inflicted on neural as well as on other structures, and should not perhaps be automatically discarded from further specialised follow-up.

\section{Acknowledgements}

This study was supported by The Spinalis Foundation the Swedish Medical Research Council (grant 06555) anc The Swedish National Board of Health and Welfare. The authors thank Ms Susanne Wikblad for excellent secretarial help, and Mr Petter Gustavsson MSc for statistical assistance.

\section{References}

1 Guttmann L. Spinal Cord Injuries: Comprehensive Management and Research, 2nd edn. Blackwell Scientific Publications: Oxford, 1976.

2 Stover SL. Spinal Cord Injury: The Facts and Figures. University of Alabama at Birmingham: Birmingham, AL, 1986.

3 Stover SL, Fine PR. The epidemiology and economics of spinal cord injury. Paraplegia 1987; 25: 225-228.

4 Whiteneck GG (ed). Aging with Spinal Cord Injury. Demos Publications: New York, 1992.

5 Whiteneck GG et al. Mortality, morbidity, and psychosocial outcomes of persons spinal cord injured more than 20 years ago. Paraplegia 1992; 30: 617-630.

6 Parsons KC, Lammertse DP. Rehabilitation in spinal cord disorders. 1. Epidemiology, prevention, and system of care of spinal cord disorders. Arch Phys Med Rehabil 1991; 72: S293-S294. 
7 Burney RE, Maio RF, Maynard F, Karunas R. Incidence, characteristics, and outcome of spinal cord injury at trauma centers in North America. Arch Surg 1993; 128: 596-599.

8 Levi R, Hultling C, Nash M, Seiger $\AA$. The Stockholm Spinal Cord Injury Study: 1. Medical problems in a regional SCI population. Paraplegia 1995; 33: 308-315.

9 American Spinal Injury Association/International Medical Society of Paraplegia (ASIA/IMSOP) The International Standards Booklet for Neurological and Functional Classification of Spinal Cord Injury. Paraplegia 1994; 32: 70-80.

10 Norusis MJ. SPSS Base System User's Guide. SPSS Inc: Chicago, 1990.

11 Hosmer DW, Lemeshow S. Applied Logistic Regression. John Wiley \& Sons: New York, 1989.

12 Everitt BS. The Analysis of Contingency Tables. Chapman \& Hall: London, 1992.
13 DeVivo MJ, Black KJ, Stover SL. Causes of death during the first 12 years after spinal cord injury. Arch Phys Med Rehabil 1993; 74: 248-254.

14 Sherwood AM, Dimitrijevic MR, McKay WB. Evidence of subclinical brain influence in clinically complete spinal cord injury: discomplete SCI. J Neurol SCI (Netherlands) 1992; 110: 90-98.

15 Samsa GP, Clifford PH, Feussner JR. Long-term survival of veterans with traumatic spinal cord injury. Arch Neurol 1993; 50: 909-914.

16 DeVivo MJ et al. The influence of age at time of spinal cord injury on rehabilitation outcome. Arch Neurol 1990; 47: $687-691$.

17 Nakajima A et al. The disease pattern and causes of death of spinal cord injured patients in Japan. Paraplegia 1989; 27: $163-171$. 